\title{
Envolvimento Gastrointestinal na Esclerose Sistémica
}

\author{
Gastrointestinal involvement in Systemic Sclerosis
}

\author{
André Real ${ }^{1}$, Cristina Lopes ${ }^{1}$, Isabel Almeida², António Marinho², Carlos Vasconcelos ${ }^{2}$ \\ ${ }^{1}$ C.H.M.T. - Hospital de Abrantes \\ ${ }^{2}$ C.H.P. - Hospital Geral Santo António (Unidade de Imunológica Clínica)
}

\begin{abstract}
Resumo
Aproximadamente 70 a 90\% dos doentes com Esclerose Sistémica apresentam envolvimento gastrointestinal e, em 10\% dos casos, este envolvimento constitui a forma de apresentação de Esclerose Sistémica. Todo 0 trato gastrointestinal pode estar afectado sendo 0 esófago 0 órgão mais frequentemente descrito $0^{1,2,3,4}$

Palabras clave: Manifestaciones gastrointestinales. Afectación gastrointestinal. Esclerosis sistémica.

Keywords: Gastrointestinal involvement. Gastrointestinal manifestations. Systemic Sclerosis.
\end{abstract}

\section{Envolvimento Gastrointestinal na Esclerose Sistémica}

A pele, o maior órgão do corpo humano, é o mais atingido pela Esclerose Sistémica (ES), seguindo-se 0 aparelho digestivo, frequentemente desvalorizado pelos clínicos ${ }^{1,2}$.

Aproximadamente 70 a $90 \%$ dos doentes apresentam envolvimento gastrointestinal (Gl), no entanto, em estudos mais recentes, $98.9 \%$ dos doente com ES apresentam patologia Gl. Em $10 \%$ dos casos de ES a patologia Gl é a forma de apresentação ${ }^{3}$.

Apesar de frequente, mais de $50 \%$ dos casos não apresentam qualquer sintomatologia no momento do diagnósti$\mathrm{CO}^{1,2,3,4}$, pelo que há autores que defendem que uma pronta referenciação a um gastroenterologista pode ser benéfica ${ }^{1}$.

Todo 0 trato Gl pode estar afectado desde a boca até ao ânus ${ }^{1,4}$, sendo 0 esófago 0 órgão mais frequentemente descrito $^{4}$, nomeadamente a função motora esofágica, causando disfagia, pirose, náuseas e refluxo gastro-esofágico pudendo originar perda de peso. Para além disso, pode favorecer 0 desenvolvimento de doença intersticial pulmonar como complicação major. 0 fígado raramente se encontra afectado? Os sintomas gastrointestinais superiores são mais frequentes que os inferiores ${ }^{5}$. A fisiopatologia do envolvimento Gl na ES ainda não está bem estabelecida. Têm sido propostas 2 fases: uma neuropática (induzida por isquemia vascular ou por compressão provocada pela deposição de colagénio) e outra miopática (por depleção de fibras de músculo liso no contexto de fibrose) $)^{2,6}$. Estudos recentes mostram a relação das manifestações gastrointestinais com a expressão de autoanticorpos, entre eles o anticorpo (Ac) anti-receptor 3 muscarinico (anti-M3R), Ac anti-nuclear (ANA) e Ac anti-centrómero (ACA) no sangue periférico ${ }^{2,6,7}$. Alterações vasculares, transtornos imunológicos, excessiva acumulação de colagénio na submucosa e atrofia do músculo liso são achados histológicos nas biopsias do trato Gl nos pacientes com ES4. A Calprotectina Fecal (FC) é um biomarcador não invasivo validado na doença inflamatória intestinal, no entanto, estudo recentes apresentam a FC como um possível biomarcador de doença $\mathrm{Gl}$ em doentes com ES ${ }^{8,9}$. Em 2 estudos semelhantes levados a cabo por Andréasson et al. ${ }^{8,9}$, a FC encontra-se elevada em doentes com ES e patologia Gl, pelo que é um biomarcador promissor da doença gastrointestinal na $\mathrm{ES}^{8,9}$.

Num estudo prospectivo com 99 doentes com ES, Savarino et al. ${ }^{10}$, observou que 0 esófago é 0 órgão mais frequentemente afetado, seguindo-se 0 intestino delgado e 0 estômago ${ }^{10}$.

Num estudo multicêntrico com 54 doentes com ES, 54\% apresentavam transtornos gastrointestinais, onde as lesões potencialmente sangrantes predominavam: ectasia vascular antral gástrica (GAVE) - 34.6\%, telangiectasias gástricas ou do intestino delgado (26.9\%) e angiodisplasia gástrica ou do intestino delgado (38.5\%). Este estudo mostrou uma forte correlação entre lesões vasculares gastrointestinais e a vasculopatia extra sistema digestivo (p. ex. úlceras digitais ${ }^{11}$.

Contudo, a mortalidade relacionada com o sistema Gl é baixa (6-12\%), no entanto tem um grande impacto na qualidade da vida diária e acarreta importantes comorbilidades 0 que, subsequentemente, afecta a sobrevida dos doente ${ }^{2}$. 0 envolvimento $\mathrm{Gl}$ severo afecta apenas $8 \%$ dos doentes com ES, no entanto quando presente a mortalidade é elevada, com apenas 15\% de sobrevida aos 9 anos $^{3}$.

0 envolvimento Gl ocorre em ambos subtipos (difusa e limitada), sendo importante ter em consideração, que a severidade cutânea e Gl podem não estar correlacionadas². Os doentes com ES, com pouca ou nenhuma afectação da pele, podem apresentar dismotilidade gastrointestinal, assim como os que apresentam afectação cutânea severa, podem não apresentar qualquer sintomatologia $\mathrm{Gl}^{6}$.

Neste artigo, faz-se uma revisão do envolvimento individual de cada órgão do tubo digestivo (cavidade oral, esófago, estômago, fígado e vias biliares, pâncreas, intestino delgado e grosso, recto e ânus). 


\section{Cavidade Oral}

0 espessamento cutâneo peribucal pode causar dificuldade na abertura da boca (microstomia) o que complica a mastigação e a higiene oral, bem como qualquer procedimento médico que implique abertura bucal (endoscopia digestiva alta - EDA, entubação oro-traqueal, etc. $)^{1,2,4}$.

Mais de $20 \%$ dos doentes apresentam sintomatologia sicca ou overlap com S. Sjogren, causando dificuldade na deglutição, doença peri-odontal, patologia da mucosa oral e gengivas, bem como disfagia oro-faringea, aumentado o risco de aspiração pulmonar ${ }^{1,2,4}$. Num estudo retrospectivo em doentes com ES, Savarino et al. ${ }^{2}$, observou alterações na radiografia de crânio, nomeadamente moderada osteólise do ângulo posterior da mandíbula e do processo coronoide². A etiologia exata da osteólise permanece incerta, no entanto existem 3 teorias principais: 0 espessamento cutâneo facial pode exercer excessiva pressão na mandíbula; a vasculopatia associada á doença pode atingir o osso, provocando isquemia e necrose óssea; e por último a atrofia dos músculos faciais podem provocar necrose óssea?2.

As opções terapêuticas estão confinadas a intervenções dietéticas (dieta liquida ou pastosa em quantidades pequenas), uso de lubrificantes / fluidos, boa higiene oral, no sentido de prevenir cáries e doença peri-odontal e muco-gengival ${ }^{2}$. A fisioterapia facial está indicada no espessamento cutâneo peri-bucal e a comissurectomia bilateral nos casos mais severos e refratários ás medidas anteriormente descritas².

\section{Esófago}

0 esófago é 0 órgão mais frequentemente afectado em doentes com ES ${ }^{1,2,3,4}$. A prevalência da dismotilidade esofágica varia entre 20 e 95\%, e parece estar associada a alterações imunológicas, à extensão do envolvimento cutâneo e à duração da doença ${ }^{2,4}$.

Diferentes mecanismos parecem explicar os transtornos esofágicos: dano vascular com hipoperfusão e isquemia; envolvimento neurogénico das alterações microvasculares nos vasa nervorum; compressão do nervo por infiltração do colagénio e / ou inflamação². Estes mecanismos induzem atrofia e substituição de músculo liso por fibrose, resultando em fraqueza das contrações musculares ${ }^{2}$. A musculatura lisa da porção média e distal do esófago é afectada, encontrando-se atrofiada e fibrosada, enquanto que a musculatura estriada da porção proximal é poupada². Para além destes mecanismos, parece estar implicada uma etiologia autoimune, já que foram encontrados autoanticorpos circulantes contra os neurónios do plexo mientérico². A acetilcolina, que atua predominantemente via M3R, é o principal neurotransmissor excitatório que regula a motilidade Gl, pelo que a presença de Ac anti-M3R parece ter um papel fundamental na génese da dismotilidade $\mathrm{Gl}^{2,6,7}$. Kawaguchi et al. ${ }^{7}$, num estudo prospectivo com 76 doentes com ES com 2 anos de duração (14 com envolvimento $\mathrm{Gl}$ e 62 sem envolvimento) e 70 controlos em que se pretendia explorar a presença do Ac anti-M3R nos doentes com ES e a sua associação com manifestações do trato Gl, demonstrou a presença do anticorpo anti-M3R em doentes com early ES e envolvimento GI7. Os achados neste estudo sugerem que há pelo menos 2 mecanismos que explicam 0 envolvimento $\mathrm{Gl}$ em doentes com early ES: desregulação colinérgica entérica causada pelo Ac anti-M3R e disfunção do músculo liso? ${ }^{7}$.

Os sintomas esofágicos iniciais são a pirose, regurgitação e a disfagia e, relacionam-se com a redução da pressão do esfíncter esofágico inferior (EEI), hérnia do hiato, ausência ou diminuição do peristaltismo esofágico e sintomatologia sic$\mathrm{Ca}^{2}$. Muitos doentes encontram-se assintomáticos ${ }^{3,4}$. Num estudo retrospectivo em que doentes com early ES e sem sintomatologia Gl realizaram endoscopia digestiva alta, observou-se esofagite em $77 \%$ dos doentes, dismotilidade da porção distal do esófago em 85\%, gastrite em 92\% e presença de H. Pylori em $38 \%{ }^{3}$. A disfunção esofágica envolve os dois terços distais do esófago incluindo o EEl hipotónico e uma importante perda de ação peristáltica, o que origina doença de refluxo gastroesofágico (DRGE), uma das manifestações mais frequentes ${ }^{1,2,4}$. A intensidade dos sintomas não se correlaciona com a gravidade da $\mathrm{DRGE}^{4}$. A esofagite erosiva está presente entre 33 e $63 \%$ dos doentes ${ }^{2}$. As complicações esofágicas da DRGE crónica são as estenoses e a metaplasia de Barrett ${ }^{1}, 2$.

A disfagia, relacionada com a dismotilidade esofágica, DRGE, estenoses, fistulas e esofagite a Candida, é tipicamente para líquidos e sólidos, exceto nas estenoses que é só para sólidos ${ }^{2,4}$. As estenoses ocorrem em 17 a 29\% dos doentes ${ }^{2}$. A esofagite a Candida deve-se sobretudo ao tratamento com terapêutica imunossupressora e ao uso crónico de inibidores da bomba de protões (IBP) $)^{2}$. A DRGE associada à ES é mais severa e traz mais complicações que a DRGE em doentes sem ES, pelo que a prevalência de esófago de Barrett e adenocarcinoma esofágico é mais elevada nos doentes com $\mathrm{ES}^{1,2,4}$.

A DRGE foi recentemente identificada como fator de risco para 0 desenvolvimento de doença intersticial pulmonar $(\mathrm{DIP})^{2,3}$. A microaspiração de conteúdo gástrico para os pulmões ${ }^{2,4}$ e a estimulação vagal desencadeada pela exposição esofágica ao ácido são os mecanismos envolvidos². Por outro lado, a DIP pode contribuir para o refluxo através do aumento da pressão inspiratória, pelo que a DRGE e a patologia pulmonar podem agravar-se mutuamente num ciclo vicioso ${ }^{2}$. Os doentes com ES e DIP têm maior morbilidade e mortalidade ${ }^{2}$. Os IBP e os fármacos procinéticos têm um papel fundamental na prevenção do desenvolvimento de DIP3. Um tratamento precoce com IBP parece reduzir as complicações da DGRE e a DIP'.

A manometria esofágica é o Gold standard na avaliação da disfagia, ganhando ainda mais importância quando a endoscopia não mostra qualquer alteraçãa $0^{1,2}$. Os achados típicos são um esófago tubular aperistáltico e um EEl hipotónico². A radiografia do esófago com bário tem pouco interesse 
no diagnóstico de ES, excepto para monitorizar o possível aparecimento de estenoses em doentes com disfagia ${ }^{2}$. Os achados radiográficos mais frequentes são a dilatação e / ou encurtamento esofágico e a hérnia do hiato².

0 tratamento tem como objetivos a redução do tempo de exposição do esófago ao ácido e a redução da incidência de DIP². 0 maior desafio do tratamento das manifestações esofágicas passa pelo controlo da dismotilidade ${ }^{1}$, implicando algumas modificações no estilo de vida, tais como, fazer várias refeições em pequena quantidade, dietas mais liquidas, emagrecimento, elevar a cabeceira da cama, cessação tabágica, abstinência alcoólica, evitar alimentos que agravem 0 refluxo, etc. ${ }^{1,2}$.

Os IBP são a base do tratamento das patologias esofágicas, no entanto os antagonistas dos receptores da histamina (H2) também podem ser usados, mas são menos eficazes ${ }^{1,2}$. Apesar do uso prolongado de IBP aumentar o risco de infecções Gl, fraturas e hipomagnesémia, o beneficio destes fármacos supera 0 risco ${ }^{1}$. 0 uso de procinéticos está indicado porque acelera o esvaziamento gástrico, reduzindo 0 reflux $0^{4}$. A cirurgia anti-refluxo está indicada nos doentes que não respondam à terapêutica médica ${ }^{4}$.

A estenoses esofágicas tratam-se por dilatação mecânica com balão esofágico via endoscópica ${ }^{1}$.

Imagens de dismotilidade esofágica:

Imagem 1. Trânsito esofágico com contraste oral positivo (bário), demonstra dilatação do lúmen esofágico. No estudo dinâmico, observase diminuição do peristaltismo esofágico, com atraso no esvaziamento do produto de contraste.

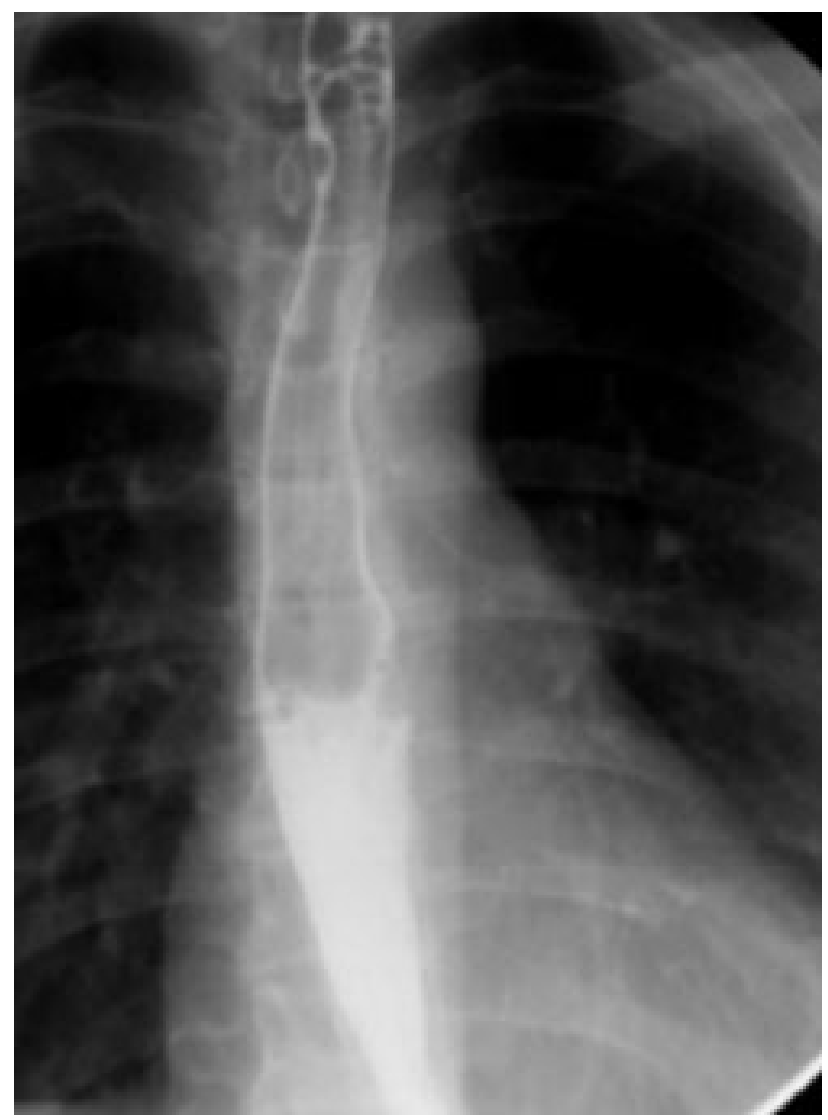

0 tratamento do esófago de Barrett passa por ablação por radiofrequência (RFA), terapia térmica endoscópica, terapia fotodinâmica, crioterapia e / ou ressecção da mucosa via endoscopia (EMR) ${ }^{1}$.

0 adenocarcinoma esofágico pode ser tratado através de RFA, EMR ou ressecção cirúrgica 1 .

\section{Estômago}

0 envolvimento gástrico está presente em pelos menos 50\% dos doentes com ES, e está associado a maior morbilidade e mortalidade nestes doentes ${ }^{2}$. As manifestações mais comuns são a gastroparesia, o esvaziamento gástrico lento, úlcera gástrica e o GAVE, também denominado watermelon stomach?2.

A gastroparesia é consequência das alterações continuas e crónicas da motilidade gástrica. 27 a 38\% destes doentes podem apresentar esvaziamento gástrico lento ou paralisia gástrica completa, causando saciedade precoce, aerocolia, dispepsia, dor abdominal, náuseas e vómitos, sintomas que podem originar e / ou agravar a DRGE com desnutrição subsequente ${ }^{1,3,4,10}$. 0 diagnóstico, para além de clinico, confirma-se por diferentes meios complementares de diagnóstico. Entre eles o electrogastrograma (EGG), a manometria, ecografia e cintigrafia com radioisótopos. As alterações no EGG incluem uma diminuição da percentagem de ondas lentas normais; na manometria observa-se hipomotilidade antral com uma amplitude baixa de contração ${ }^{2}$. Em estados iniciais da doença, antes do depósito extenso de colagénio, o tratamento sintomático é a estratégia inicial e, inclui procinéticos como a metoclopramida, domperidona ou eritromicina, entre outros. Este ultimo, devido á sua estrutura química semelhante á hormona motilina, tem uma papel adicional no controlo da motilidade no trato gastrointestinal' ${ }^{1}$. Em 2 case reports, 0 uso de prucalopride (5-HT4) resolveu por completo os sintomas gastrointestinais ${ }^{2}$. Num estudo duplamente-cego, Ariyasu et al. ${ }^{11}$, mostrou 0 efeito benéfico da grelina em doentes com esvaziamento gástrico, concluindo que esta acelera o esvaziamento, melhorando a sintomatologia ${ }^{11}$. Os doentes refractários ao tratamento sintomático, que têm dificuldade em manter uma correta nutrição, hidratação e / ou quantidade necessária de electrólitos, podem necessitar de uma sonda naso-entérica, gastrostomia ou jejunostomia percutânea. Os que não tolerarem estas medidas invasivas têm indicação para alimentação parentérica total1 .

As lesões vasculares associadas á ES vão desde pequenas telangiectasias até lesões mais extensas chamada ectasia vascular antral gástrica ${ }^{12}$. As formas de apresentação clinica de GAVE variam desde formas mais benignas, como anemia por deficit de ferro, até situações graves como hemorragia Gl severa ${ }^{2,3,13}$. A anemia encontra-se presente em 96\% dos doentes com GAVE ${ }^{3,12}$. Estima-se que a prevalência de GAVE varia entre 5.7 e 14\%4. 0 diagnóstico estabelece-se por endoscopia digestiva alta, onde se pode observar múltiplas, paralelas e longitudinais colunas de vasos vermelhos no antro gástrico em direção ao piloro 2,3,4 . Segundo um estudo realizado por Marie et al, a prevalência de GAVE é semelhante 
em doentes com ES limitada e difusa, no entanto, um estudo mais recente mostra que o subtipo difuso está associado a um desenvolvimento precoce de GAVE, bem como anemia grave ${ }^{2,3}$. Atualmente existe alguma controvérsia acerca da relação entre o GAVE e os Ac anti-RNA polimerase III, já que enquanto alguns estudos mostram uma associação positi$v^{1}{ }^{1,2,12}$, noutros não existe ${ }^{3,14}$. Savarino et al. ${ }^{2}$, observou que 0 GAVE é uma manifestação precoce em doentes com ES e, pode inclusive, preceder as manifestações cutâneas, pelo que doentes com GAVE devem fazer o despiste de $\mathrm{ES}^{2,4,14}$. Ghrénassia et al. ${ }^{12}$, num estudo multicêntrico com 49 doentes com ES e GAVE vs grupo controlo com ES, observou que a sobrevida aos 30 meses é semelhante entre doentes com ES e GAVE e o grupo controlo, no entanto apresentam um risco maior de desenvolverem crise renal ${ }^{12}$. Em relação ao tratamento, para além das medidas de suporte, incluindo a reposição de ferro e a transfusão de concentrado de eritrócitos, a ablação endoscópica é o tratamento de primeira linha em doentes com hemorragia Gl no contexto de GAVE. Apesar da terapêutica imunossupressora com ciclofosfamida ter sido descrita como benéfica em casos severos, na ausência de resposta ás medidas acima descritas (casos refractários) está indicada a antrectomia².

A gastrite, pode ou não estar associada ao Helicobacter pylori. Se presente este deve ser erradicado, já que o risco de ulceração e hemorragia Gl subsequente é muito maior nos doentes que se apresentam com H. pylori'.

A desnutrição nos doentes com ES é a consequência da malabsorção relacionada com 0 sobrecrescimento bacteriano no intestino delgado (SIBO) ou com os distúrbios de motilidade acima descritos. Todos os doentes com ES devem fazer o rastreio da desnutrição, que se caracteriza pelo questionário MUST (malnutrition universal screening tool), controlo da perda de peso e vigilância através do BMI (índex de massa corporal) $)^{3}$.

Imagens de GAVE:

Imagem 2. EDA - "estômago em melancia" (watermelon stomach).

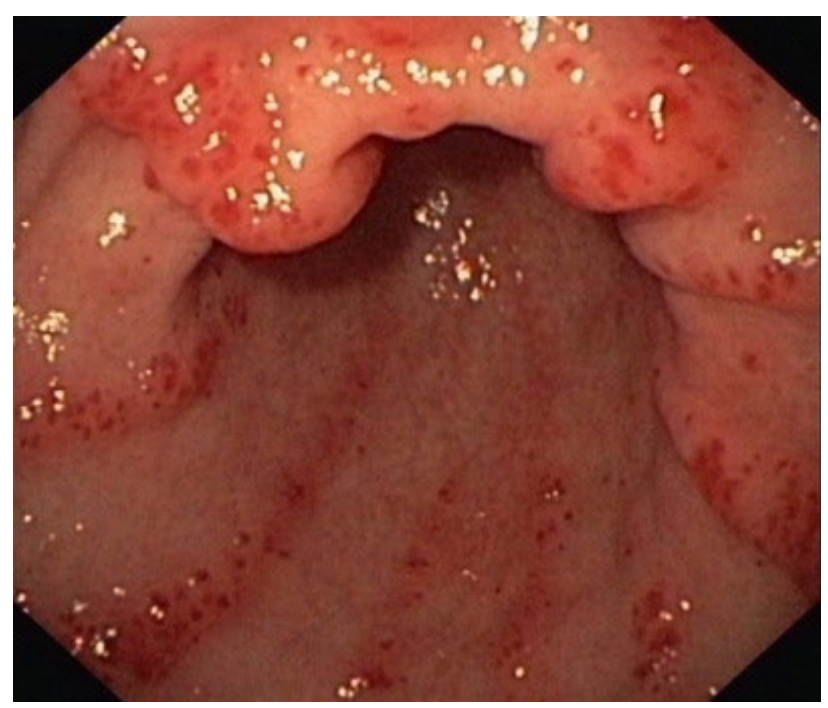

\section{Fígado e vias biliares}

Apesar da ES ser uma doença autoimune com envolvimento sistémico, 0 dano hepático e das vias biliares é raro ${ }^{1,2,4}$, pelo que a presença de citólise hepática deve fazer-nos suspeitar, em primeiro lugar, de hepatite aguda ou crónica de outras etiologias (p. ex. viricas e /ou toxicidade medicamentosa)1. Num estudo retrospectivo post-mortem em doentes com ES, achados como hepatomegalia e cirrose foram mais frequentemente encontrados no grupo controlo do que em doentes com ES².

A cirrose biliar primária (CBP) é uma doença hepática colestática crónica que se caracteriza por colangite não supurativa imuno-mediada que afecta sobretudo os ductos biliares septais e inter-lobulares². É a manifestação hepato-biliar mais frequente em doentes com ES, estimando-se uma prevalência de 2,5\% $\%^{4}$. Está associada á presença de Ac anti-mitocondriais (AMA) ${ }^{2,15}$. Aproximadamente $5 \%$ dos doentes com ES apresentam AMA positivos, e o ACA, está presente em $25 \%$ dos doentes com CBP2. Tendo em conta que os AMA precedem em média 5 anos a sintomatologia da CBP, os doentes que apresentam positividade para este Ac requerem atenção e monitorização com vista a uma detecção precoce dos sinais e sintomas associados á doença hepática ${ }^{2,15}$. Tian et al. ${ }^{4}$, mostrou que a prevalência dos autoanticorpos associados á CBP pode ser mais elevada se os AMA estiverem incluídos no rastreio autoimune, pudendo melhorar a detecção de CBP em doentes com ES ${ }^{4}$. 0 aparecimento da CBP pode preceder, surgir concomitantemente, ou mais frequentemente após 0 inicio da $\mathrm{ES}^{4}$. A elevação da fosfatase alcalina sérica sugere que a colestase pode dever-se à destruição progressiva dos ductos inter-lobulares secundário ao processo autoimune na CBP.

0 tratamento da ES pode incluir fármacos hepatotóxicos pelo que, na presença de CBP, a gestão destes doentes é mais complexa e desafiante'.

Embora a terapêutica com ácido ursodesoxicólico esteja indicada, o seu beneficio mantem-se controverso. Quando 0 envolvimento hepático é severo, alguns doentes podem necessitar de transplante 4 .

Está descrita na literatura a associação entre colangite esclerosante primária e ES, facto que se explica pela deposição anómala de colagénio no epitélio dos ductos biliares².

You et al..$^{15} \mathrm{e}$ Pamfil et al. ${ }^{16}$ descreveram 2 casos de hepatite autoimune (HAl) com ES. Doentes com ES e elevação persistente das enzimas hepáticas, sem outra causa subjacente, devem ser rastreados para HA ${ }^{15,16}$. A fisiopatologia da HAl em doentes com ES permanece por esclarecer, no entanto parecer dever-se a disfunção da imunidade celular e humoral relacionada com a ES, sendo o ACA detectado em mais do que $15 \%$ dos doentes com HAl ${ }^{15}$.

Tendo em conta a dismotilidade da vesícula biliar, vários estudos avaliaram a possível correlação entre ES e patologia da vesícula biliar, no entanto os resultados não evidenciaram uma aumento do risco de colelitiase em doentes com ES². 
Os resultados da literatura quanto à prevalência da doença celíaca (DC) na ES têmse mostrado algo controversos. Dois estudos diferentes acharam uma prevalência de aproximadamente $8 \%$ de DC na ES, enquanto que num estudo retrospectivo, Forbess et al. ${ }^{17}$ estudou a prevalência da doença celíaca em doentes com ES, associando sintomatologia gastrointestinal com os autoanticorpos característicos da doença celíaca (Ac anti-transglutaminasa, anti-gliadina e anti-endomíssio), não se tendo verificado diferenças em relação ao grupo controlo, defendendo que o rastreio desta patologia não está indicado nos doentes com ES ${ }^{17}$.

\section{Pâncreas}

A patologia pancreática é pouco frequente nos doentes com ES, mas pode ocorrer ${ }^{2}$. Frequentemente, a sintomatologia de má absorção pancreática é confundida com SIBO. A má absorção dos lípidos, pode observar-se no teste qualitativo das fezes e confirmada pelo teste quantitativo de colheita de fezes durante $72 \mathrm{~h}$. Se a esteatorreia não melhora com a antibioterapia, deveremos suspeitar de patologia pancreática².

Tendo em conta a insuficiência exócrina na patologia pancreática associada à ES, está indicada a administração de suplementos de enzimas pancreáticas².

\section{Intestino delgado}

Depois do esófago, o intestino delgado é a porção mais frequentemente afectado. Em aproximadamente $40 \%$ dos doentes com ES, 0 intestino delgado está afectado ${ }^{4}$, no entanto, vários estudos demonstraram alterações da motilidade intestinal em $80 \%$ dos doentes 2 .

Dentro das patologias do intestino delgado incluem-se a pseudo-obstrução intestinal crónica (CIP0), telangiectasias intestinais, wide mouth diverticula, alterações da motilidade que podem aumentar a incidência de SIBO e a pneumatose cistoide intestinal ${ }^{1}$. A patologia intestinal associada á ES caracteriza-se por disfunção da motilidade e dano da mucosa Gl. Tal como já foi referido, factores miogénicos (fibrose do músculo liso) e neurogénicos (disfunção do sistema nervoso autónomo) estão envolvidos na patogenia destas alterações ${ }^{2}$. Enquanto alguns estudos não encontram correlação entre autoanticorpos e manifestações gastrointestinais, a presença do Ac. Anti-M3R parece estar implicada na disfunção motora $\mathrm{Gl}^{2,6,7}$. A fase precoce das manifestações $\mathrm{Gl}$ caracteriza-se por obstipação, enquanto que em estados mais avançados da doença, quando a malabsorção e a diarreia já estão presentes, os sintomas predominantes são a dor abdominal e a aerocolia. Estas manifestações tardias devem-se ao SIBO e à disfunção ano-rectal2 .

A pseudo-obstrução é uma complicação secundaria à hipomotilidade do intestino delgado, já que uma diminuição ou a ausência de peristaltismo pode provocar uma dilatação do lúmen e overt pseudo-obstruction subsequente. Tendo em conta que o depósito de colagénio na parede do intestino delgado é irreversível, é frequente a recorrência de pseu- do-obstruções, tornando-se por isso num processo crónico $(\mathrm{CIPO})^{4}$. Caracteriza-se por distensão abdominal, dor, obstipação ou diarreia alternando com obstipação². 0 tratamento inicial baseia-se na pausa alimentar, fluidoterapia endovenosa e correção electrolítica. 0 octreótido tem mostrado ser eficaz, começando com $50 \mu \mathrm{g} 2$ vezes dia, no entanto a dose pode aumentar-se até $200 \mu \mathrm{g}$, se não tiver havido resposta. Em doentes com episódios recorrentes, $50 \mu \mathrm{g}$ de octreótido ao deitar parece ser eficaz. A neostigmina parece ser igualmente eficaz, já que descomprime 0 cólon. Em casos refractários ao octreótido e à neostigmina, a descompressão com o colonoscópio é o tratamento de eleição, estando os procedimentos cirúrgicos reservados para os casos de peritonite ou perfuração $0^{4}$.

As telangiectasias do intestino delgado causam perda crónica de sangue, manifestando-se por anemia ${ }^{1,2}$. Podem ser visualizadas por vídeo-cápsula. Contudo, em doentes com hipomotilidade severa, existe o risco da cápsula ficar retida numa parte do tubo digestivo ${ }^{1}$. As lesões podem ser tratadas por técnicas de enteroscopia endoscópicas ${ }^{1}$. Wide mouth diverticula pode ser observado em doentes com motilidade normal ou diminuída e, podem originar SIBO ${ }^{1}$. A dismotilidade intestinal encontra-se presente entre 40 a $88 \%$ dos doentes com ES. A manometria e os estudos electrofisiológicos apontam para uma neuropatia do sistema nervoso entérico nos doentes com dismotilidade intestinal na ES, e o Ac Anti- M3R também está presente neste tipo de doentes. A hipomotilidade intestinal provoca náuseas, vómitos, aerocolia, distensão abdominal, anorexia e dor abdominal. A diminuição da motilidade origina estase do conteúdo intestinal, o que por sua vez, desencadeia SIBO. A definição de SIBO é a presença de mais de $1 \times 105$ microorganismos por milímetro de aspirado duodenal / jejuno ${ }^{1,4}$. Está presente em mais de $55 \%$ dos doentes com ES, e é mais prevalente no subtipo limitada. Esta entidade compete com 0 hospedeiro pela nutrição, causando malabsorção de gorduras, proteínas, hidratos de carbono e vitaminas ${ }^{4}$. Por este motivo, os doentes que desenvolvem SIBO têm níveis mais baixos de albumina, proteínas totais, vitamina $B 12$ e ferritina ${ }^{1,4}$. Os sintomas assemelham-se aos da hipomotilidade do intestino delgado, contudo pode desenvolver esteatorreia, múltiplos deficits nutricionais e perda de peso, quando a sobrecrescimento bacteriano é sever $0^{4}$. Frequentemente, 0 diagnóstico faz-se a través dum teste de respiração barato e não invasivo, analisando 0 hidrogénio exalado ${ }^{2}$. A base do tratamento é a antibioterapia $^{1,2,4}$. Sempre que possível devem utilizar-se antibióticos sem absorção intestinal, tal como a rifampicina². Outros antibióticos possíveis são o metronidazol (500 mg BID) ou

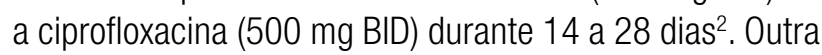
alternativa são 0 cloranfenicol e as cefalosporinas de terceira geração. Nos casos crónicos, é importante fazer switch da antibioterapia para evitar resistências bacterianas. Os probióticos como o lactobacillus parecem ser eficazes e seguros nos doentes com aerocolia causada pelo SIBO ${ }^{4}$. 
Imagem 3. Radiografia do abdómen com contraste oral, onde se observa dilatação anormal das ansas do cólon (megacólon).

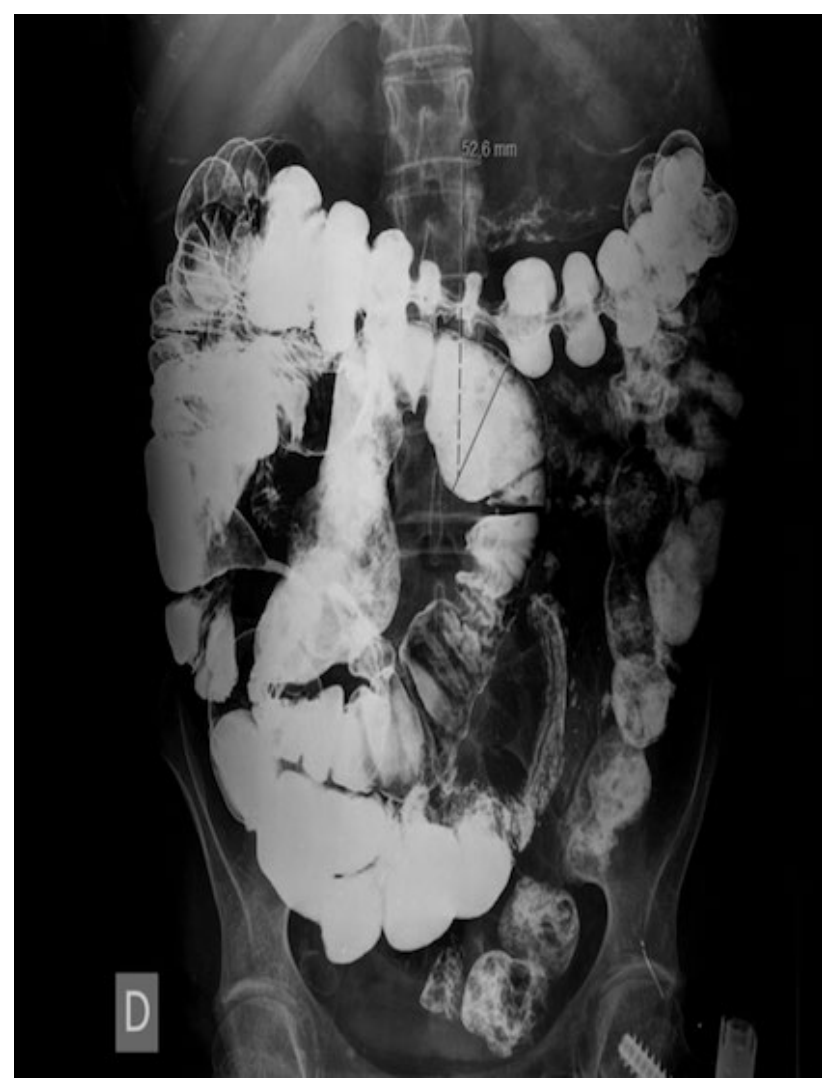

A lavagem cíclica com preparações de polietileno glicol é útil para diminuir o número de bactérias, assim como 0 octreótido e procinéticos que reduzem a estase intestinal favorecendo 0 aparecimento de SIBO ${ }^{1} .0$ octreótido, $50 \mu \mathrm{g}$ subcutâneo ao deitar, estimula a motilidade intestinal, reduz 0 aparecimento de SIBO e melhora a sintomatologia'.

A pneumatose cistoide intestinal, condição rara associada a doentes com ES, caracteriza-se pela presença de ar na parede intestinal (intramural) sendo secundária à dismotilidade do intestino delgado. As manifestações clinicas vão desde doentes assintomáticos até dor abdominal severa, diarreia ou esteatorreia. A ruptura dos quistos origina um pneumoperitoneu benigno (estéril) ${ }^{1,4}$. Trata-se sobretudo de um diagnóstico radiológico ${ }^{4}$. 0 tratamento inclui medidas de suporte, antibióticos e raramente ressecção cirúrgica ${ }^{1,4}$. Guman et al. ${ }^{18}$, num Clinical Series descreveu 3 doentes com pneumatose cistoide intestinal, 2 overlap (com S. Sjogren e polimiosite) e um associado a ES limitada. Este último trata-se duma mulher de 76 anos com clinica de obstrução intestinal pelo que foi submetida a laparotomia exploradora, sem se ter visualizado qualquer sinal de obstrução mecânica ou perfuração. Durante meses recorreu frequentemente ao Serviço de Urgência pelo mesmo quadro clinico, com agravamento progressivo e prostração acentuada, até que realiza TAC abdominal que evidenciou coleções de ar intramural, tendo iniciado antibioterapia com reversão do quadro clinico ${ }^{18}$.
Imagem 4. 2 angiectasias no cego coaguladas com árgon plasma.

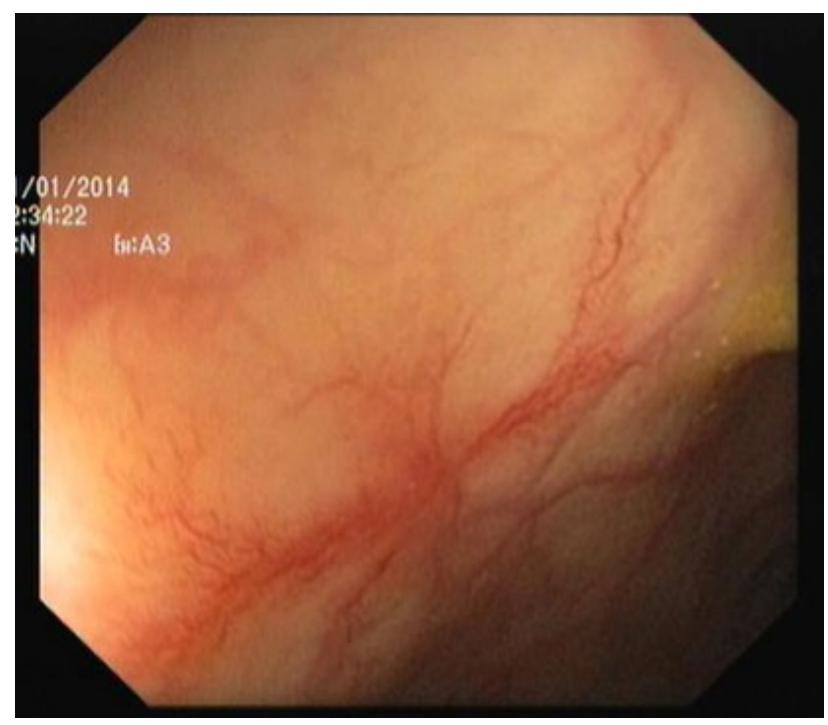

\section{Cólon}

0 envolvimento do cólon observa-se em 10 a 50\% dos doentes com ES ${ }^{4}$. A hipomotilidade cólica é a afectação mais comum, pudendo causar um transito intestinal lento e, por conseguinte obstipação e dificuldade em evacuar. Contudo a obstipação nem sempre persiste já que um trânsito intestinal lento favorece o surgimento de SIBO e, consequentemente, diarreia ${ }^{1,4}$. A obstipação e a diarreia são as manifestações mais comuns ${ }^{1,4}$. Podem encontrar-se wide-mouth diverticula, mas raramente são sintomáticos. Telangiectasias colónicas podem estar presentes em doentes com ES e causar hemorragia $\mathrm{Gl}^{4}$. A fibrose, atonia e distensão (megacólon) com ausência das haustras são características de doenças avançada ${ }^{1,2}$.

0 tratamento inclui o controlo sintomático da obstipação com uma dieta com fibra, ingestão de fluidos, polietileno glicol, laxantes osmóticos (lactulose e bisacodilo), antibióticos (no caso de SIBO) e probióticos ${ }^{1,4}$.

\section{Ânus e recto}

A prevalência do envolvimento ano-rectal é entre 50-70\%3,4. A incontinência fecal pode ser observada nos doentes com ES em aproximadamente 37 a $70 \%$ dos casos, no entanto pensa-se que esta prevalência está subestimada, já que muitos doentes têm vergonha em descrever os sintomas ${ }^{4}$. Tendo em conta que a ES afecta predominantemente o músculo liso e que 0 esfíncter anal interno (EAl) é constituído por músculo liso, a sua afetação leva a um EAl atrófico, o que em associação com a neuropatia e / ou disfunção sensorial ou motora ano-rectal (dano no reflexo inibitório ano-rectal), desempenham um papel fundamental na fisiopatologia ano-rectal ${ }^{1,2,3,4}$. Muitos estudos mostraram que na incontinência fecal, os doentes com ES apresentam uma pressão anal em repouso diminuí$\mathrm{da}^{4}$. Thoua et al. ${ }^{19}$, demonstrou que em doentes com ES é frequente, de forma sintomática ou assintomática, o envolvimento anorectal, possuindo em ambos casos um EAl atrófico e fino $0^{3,19}$. 
0 prolapso rectal é raro, no entanto, quando presente agrava a disfunção do esfíncter anal e por isso, a incontinência fecal ${ }^{1}$. Outros sintomas descritos são a dor durante a defecação, diarreia crónica e tenesmo ${ }^{1,4}$. 0 tratamento baseia-se no controlo da obstipação com ingestão de fluidos, laxantes osmóticos como lactulose e bisacodilo e dietas com fibras 4 . Em relação á diarreia e / ou incontinência, estão indicados solidificantes para as fezes e estimulação do nervo sagrado². Frequentemente é necessário recorrer à cirurgia, sobretudo nos casos de prolapso rectal2. Estes doentes podem beneficiar em ser observados por um cirurgião especializado em doenças do pavimento pélvico ${ }^{\top}$.

\section{Bibliografia}

1. Kirby DF and Chatterjee S. Evaluation and management of gastrointestinal manifestations in scleroderma. Curr Opin Rheumatol 2014; 26:621-9.

2. Savarino E, Furnari M, Bortoli N, Martinucci I, Bodini G, Ghio M, et al. Gastrointestinal involvement in systemic sclerosis. Presse Med 2014 Oct; 4: e279-91.

3. Giger $\mathrm{G}$ and Baron M. Gastrointestinal manifestations of scleroderma: recent progress in evaluation, pathogenesis, and management. Curr Rheumatol Rep 2012 Feb; 14(1): 22-9.

4. Tian XP and Zhang X. Gastrointestinal complications of systemic sclerosis. World J Gastroenterol 2013 November 7; 19(41): 7062-68

5. Wielosz E, Borys 0, Zychowska I, Majdan M. Gastrointestinal involvement in patients with systemic sclerosis. Pol Arch Med Wewn 2010; 120(4): 132-6

6. Matucci-Cerinic M and Czirják L. Immune-endothelial-nerve interaction: an explanation for the failure of the gastrointestinal system in systemic sclerosis? Ann Rheum Dis May 2009; 68(5): 609-10.

7. Kawaguchi Y, Nakamura Y, Matsumoto I, Nishimagi E, Satoh T, Kuwana M, et al. Muscarinic-3 acetylcholine receptor autoantibody in patients with systemic sclerosis: contribution to severe gastrointestinal tract dysmotility. Ann Rheum Dis 2009 May; 68(5): 710-4.
8. Andréasson K, Saxne T, Scheja A, Bartosik I, Mandl T, Hesselstrand R. Faecal levels of calprotectin in systemic sclerosis are stable over time and are higher compared to primary Sjögren's syndrome and rheumatoid arthritis. Arthritis Research \& Therapy 2014; 16: R46.

9. Andréasson K, Scheja A, Saxne T, Ohlsson B, Hesselstrand R. Faecal calprotectin a biomarker of gastrointestinal disease in systemic sclerosis. J Intern Med 2011 270: 50-7.

10. Savarino E, Mei F, Parodi A, Ghio M, Furnari M, Gentile A, et al. Gastrointestinal motility disorder assessment in systemic sclerosis. Rheumatology 2013; 52(6): 1095-1100.

11. 11. Aryiasu H, Iwakura H, Yukawa N, Murayama T, Yokode M, Tada H, et al. Clinica effects of ghrelin on gastrointestinal involvement in patients with systemic sclerosis. Endocrine Journal 2014; 61(7): 735-42.

12. Ghrénassia E, Avouac J, Khanna D, Derk CT, Distler 0 , Suliman YA et al. Prevalence, correlates and outcomes of gastric antral vascular ectasia in systemic sclerosis: a EUSTAR case-control study. J Rheumatol 2014; 41: 99-105.

13. Mohan $P$ and Venkataraman J. Upper gastrointestinal bleed in a woman with systemic sclerosis. Clinics and Research in Hepatology and Gastroenterology 2011; 35:83-84

14. Hung EW, Mayes MD, Sharif R, Assassi S, Machicao VI, Hosing C, et al. Gastric antra vascular ectasia and its clinical correlates in patients with early diffuse systemic sclerosis in the SCOT trial. J Rheumatol 2013 April; 40(4): 455-60.

15. You BC, Jeong SW, Jang JY, Goo SM, Kim SG, Kim YS, et al. Liver cirrhosis due to autoimmune hepatitis combined with systemic sclerosis. Korean J Gastroenterol 2012; 59 (1): 48-52.

16. Pamfil C, Zdrenghea MT, Mircea PA, Manzat Saplacan RM, Rednic N and Rednic S. Systemic sclerosis-polymyositis overlap syndrome associated with autoimmune hepatitis and cerebral vasculitis. J Gastrointestin Liver Dis September 2012; 21(3): 317-20.

17. Forbess LJ, Gordon JK, Doobay K, Bosworth BP, Lyman S, Davids ML, et al. Low prevalence of coeliac disease in patients with systemic sclerosis: a crosssectional study of a registry cohort. Rheumatology 2013; 52: 939-43.

18. Guman A, Brook 0, Chermesh I and Moscovici Y. Pneumatosis cystoides intestinalis in scleroderma-related conditions. Internal Medicine Journal 2012; 323-329.

19. Thoua N, Schizas A, Forbes A, Denton CP and Emmanuel AV. Internal anal sphincter atrophy in patients with systemic sclerosis. Rheumatology 2011; 50: 1596-602. 